\title{
PROFIL USAHA PENANGKAPAN LOBSTER DI PESISIR PANTAI SADENG, KABUPATEN GUNUNGKIDUL
}

\author{
Subhechanis Saptanto \\ Balai Besar Penelitian Sosial Ekonomi Kelautan dan Perikanan \\ JI. KS. Tubun Petamburan VI Jakarta 10260 \\ Telp. (021) 53650162, Fax. (021)53650159 \\ e-mail: anis_saptanto@yahoo.com
}

Diterima 3 Juli 2012- Disetujui 22 Nopember 2013

\begin{abstract}
ABSTRAK
Lobster merupakan salah satu komoditas perikanan yang memiliki nilai ekonomis tinggi, harganya mencapai Rp 650.000,- per kg. Pantai Sadeng adalah salah satu pangkalan pendaratan ikan yang terletak di Kabupaten Gunungkidul, Yogyakarta yang banyak menghasilkan lobster. Tulisan ini bertujuan untuk memberikan gambaran usaha penangkapan lobster yang ada di Sadeng. Waktu pengambilan data dilakukan pada Bulan September 2013. Jenis data yang digunakan dalam penelitian ini adalah data sekunder dan primer. Data sekunder berasal dari data statistik perikanan Kabupaten Gunungkidul, sedangkan data primer berasal dari wawancara mendalam dengan responden nelayan terpilih. Hasil penelitian menunjukkan bahwa biaya yang dikeluarkan oleh nelayan untuk menangkap lobster per trip sebesar Rp 200.000,-. Penangkapan lobster sangat tergantung pada musim penangkapan. Musim puncak biasanya mulai dari bulan Oktober sampai Desember. Musim paceklik terjadi pada bulan Mei sampai September dan musim normal di bulan Januari hingga April. Oleh karena itu, lobster harus dijaga kelestariannya. Penangkapan dikendalikan dengan menggunakan alat tangkap yang ramah lingkungan.
\end{abstract}

Kata kunci: lobster, Sadeng, nelayan

Abstract : Profile of Lobster Fishing Activity in Sadeng Coastal Area, Gunungkidul District. By Subhechanis Saptanto.

Lobster is one of fisheries commodity that has high economic value because of the high selling price, which can reach Rp 650.000,-/ $/ \mathrm{kg}$. Sadeng is one of the region that produce many lobster, a small fish port that located in Gunungkidul District, DI Yogyakarta Province. This paper was aimed to provide an overview of the lobsters fishing in Sadeng. Data collection was conducted in September 2013. Primary and secondary data was used in the research. Primary data was collected by in depth interview method with key respondents. Meanwhile, secondary data based on fisheries statistic data in Gunungkidul District. The result shows that variable costs of lobster fishing activity is Rp 200.000,-/trip. Total catch of lobster is depend on fishing season. Peak season usually from October until December. Famine season occured in May through September and common started from January to April. Therefore, lobster should be protected. Environmentally friendly fishing gear might be used to control the lobster production.

Keywords : lobster, sadeng, fishers

\section{PENDAHULUAN}

Lobster merupakan salah satu komoditas perikanan yang memiliki nilai ekonomis penting karena memiliki harga jual yang tinggi. Salah satu wilayah penghasil lobster adalah Provinsi Daerah Istimewa Yogyakarta tepatnya berada di Pangkalan Pendaratan Ikan (PPI) Sadeng. Banyak nelayan yang berdomisili di Pantai Sadeng menangkap lobster untuk mencukupi kebutuhan hidupnya. PPI Sadeng terletak di Desa
Songbanyu dan Desa Pucung, Kecamatan Girisubo, Kabupaten Gunungkidul, Provinsi DI Yogyakarta dan berjarak sekitar $90 \mathrm{~km}$ ke arah timur ibukota provinsi.

Jenis lobster yang sering ditangkap oleh nelayan adalah jenis Panulirus ornatus (lobster mutiara), Panulirus penicillatus (lobster batu), Panulirus homarus (lobster hijau pasir) (http://vunisatiarahayu.blogspot. com, 2008) seperti yang terlihat pada Gambar 1 sebagai berikut.

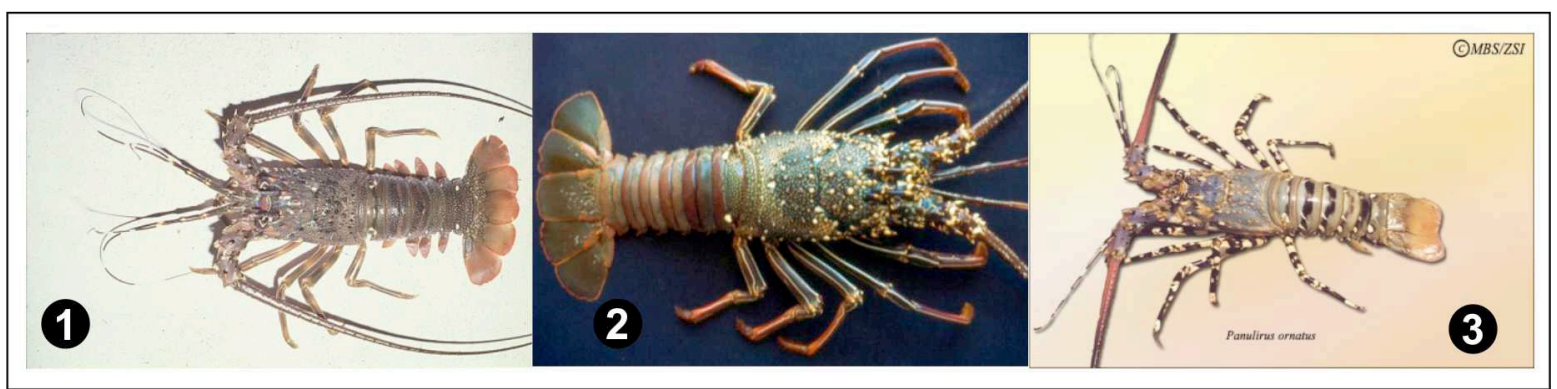

Gambar 1. Jenis-jenis Lobster yang Banyak Ditangkap di Sadeng : 1) P. homarus; 2). P. penicillatus; 3) P. ornatus (Sumber : Dikutip dari berbagai sumber) 
Penangkapan lobster pada umumnya dapat dilakukan dengan dua jenis alat tangkap yaitu krendet (sejenis perangkap) dan jaring gillnet (BBPI Semarang, 1996). Pada tahun 2012 jumlah tangkapan lobster di Kabupaten Gunungkidul mencapai 88,27 ton atau sekitar 3,24\% total hasil tangkapan laut Gunungkidul. Terjadi peningkatan yang signifikan dari tahun 2011 ke tahun 2012 dimana pada pada tahun 2011 produksi lobster hanya berjumlah 19,4 ton. Hal ini terjadi karena ada kebijakan dari Dinas Kelautan dan Perikanan Gunungkidul yang mendorong nelayan untuk memperbanyak hasil tangkapan (Antara, 2011).

Berdasarkan hal tersebut di atas maka tulisan ini bertujuan untuk menggambarkan profil nelayan yang melakukan penangkapan di wilayah Sadeng.

\section{METODOLOGI}

Data yang dikumpulkan adalah data primer dan sekunder. Data primer terdiri dari data sosial ekonomi nelayan. Data tersebut diperoleh melalui wawancara dengan responden kunci yakni nelayan yang melakukan kegiatan penangkapan lobster sedangkan data sekunder meliputi data statistik dari Dinas Kelautan dan Perikanan Kabupaten Gunungkidul. Pengumpulan data dilakukan pada Bulan September 2013 di PPI Sadeng. Data yang telah dikumpulkan tersebut kemudian dianalisis menggunakan analisis statistik deskriptif sederhana guna mengetahui perkembangan hasil tangkapan lobster di wilayah Gunungkidul secara umum dan wilayah Sadeng secara khusus.

\section{HASIL DAN PEMBAHASAN}

\section{Pendaratan dan Musim Penangkapan Lobster}

Pada tahun 2012 produksi lobster di Gunungkidul sebanyak 88,27 ton, $31,78 \%$ berasal dari Sadeng, $29,72 \%$ dari Ngrenehan dan sisanya berasal dari Gesing, Baron, Drini, Ngandong, Siung, Nampu dan Purwosari. Produksi lobster per wilayah dapat dilihat pada Gambar 2 sebagai berikut.

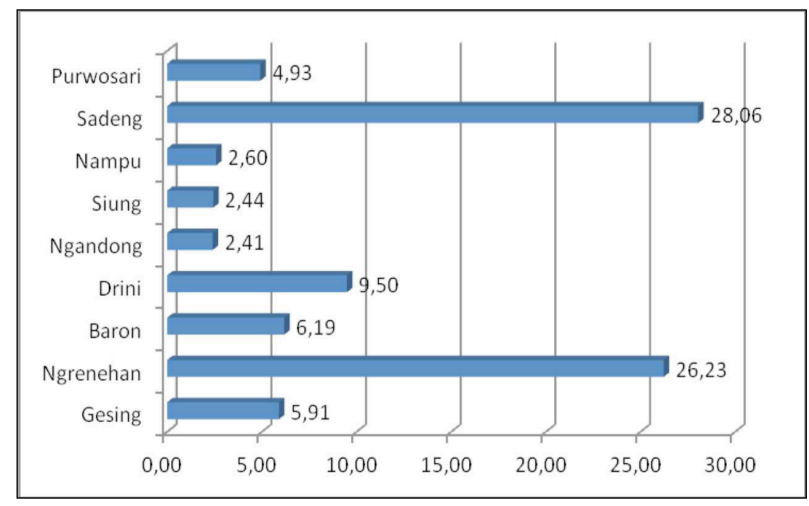

Gambar 2. Diagram Batang Jumlah Produksi Lobster (Ton) per Wilayah di Kabupaten Gunungkidul Tahun 2012.

Sumber : Dinas Kelautan dan Perikanan Kabupaten Gunungkidul, 2012
Produksi bulanan komoditas lobster di Kabupaten Gunungkidul sangat berfluktuasi karena sangat tergantung dengan musim penangkapan. Pada bulan Oktober hingga Desember hasil tangkapan mencapai musim puncak sedangkan bulan Mei hingga September dalam kondisi musim paceklik karena hasil tangkapan yang sedikit dan pada bulan Januari hingga April merupakan musim sedang. Menurut data dari Dinas Kelautan dan Perikanan Kabupaten Gunungkidul, produksi rata-rata bulanan lobster selama tahun 2012 adalah sebesar 7,36 ton/bulan. Pada Gambar 3 berikut ditampilkan fluktuasi jumlah produksi bulanan komoditas lobster di Kabupaten Gunungkidul.

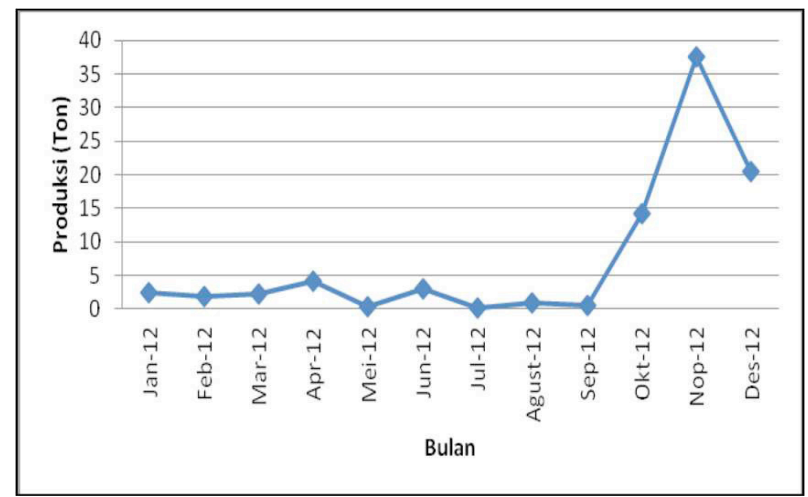

Gambar 3. Fluktuasi Jumlah Produksi Lobster Bulanan di Kabupaten Gunungkidul tahun 2012.

Sumber : Dinas Kelautan dan Perikanan Kabupaten Gunungkidul, 2012

\section{Produksi Lobster di Sadeng}

Wilayah Sadeng merupakan tempat tinggal nelayan baik yang menggunakan armada tradisional hingga modern. Salah satu nelayan tradisional yang cukup banyak terdapat di Sadeng adalah nelayan penangkap lobster. Bagi nelayan penangkap lobster, lobster merupakan sumber penopang perekonomian keluarganya karena lobster merupakan salah satu komoditas perikanan yang memiliki nilai ekonomis tinggi karena per kg bisa mencapai harga Rp 400.000,- hingga Rp 650.000,- untuk jenis lobster mutiara. Pada Gambar 4 ditampilkan Pantai Sadeng dan armada perikanan yang ada.

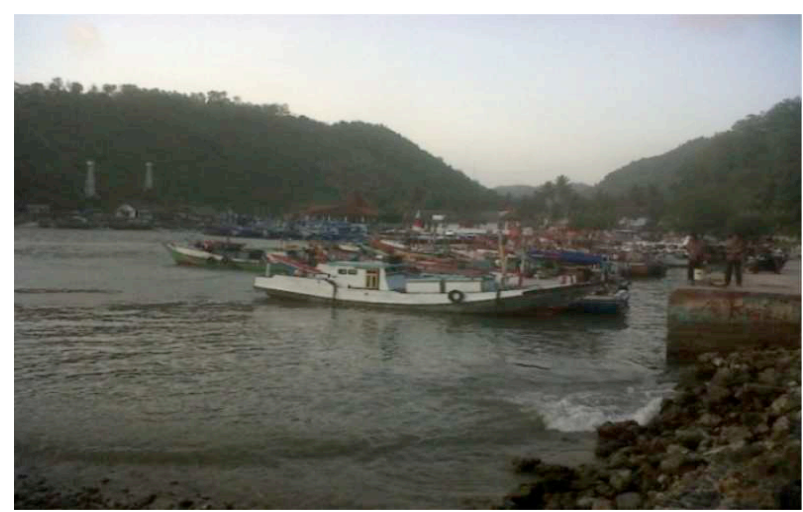

Gambar 4. Suasana Pantai dan Armada Penangkapan di Sadeng.

Sumber : Dokumen Pribadi, 2013 
Hasil tangkapan lobster tertinggi di Sadeng terdapat pada bulan Nopember yang mencapai sekitar 10,35 ton sedangkan terendah pada bulan September dimana tidak ada hasil tangkapan. Rata-rata produksi bulanan lobster dari wilayah Sadeng sekitar 2,34 ton/ bulan. Fluktuasi produksi bulanan lobster dari wilayah Sadeng dapat dilihat pada Gambar 5 sebagai berikut.

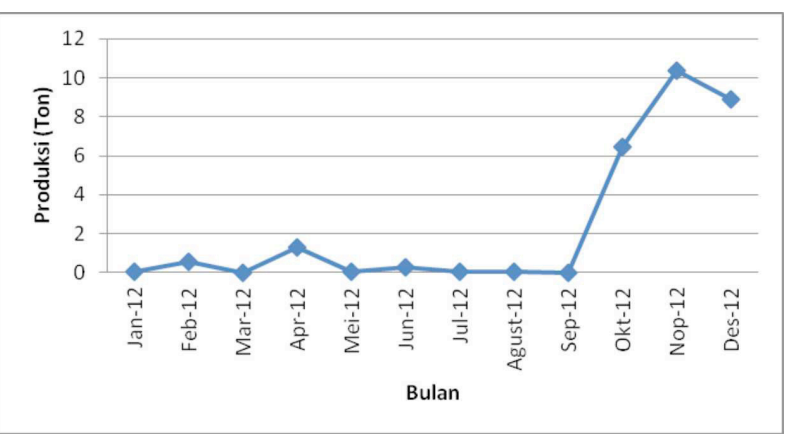

Gambar 5. Fluktuasi Jumlah Produksi Lobster Bulanan di Sadeng tahun 2012.

Sumber : Dinas Kelautan dan Perikanan, 2012

\section{Profil Nelayan Penangkap Lobster}

Penangkapan lobster di Sadeng masih dilakukan secara tradisional. Hal ini terlihat dari penggunaan armada kurang dari 3 GT, alat tangkapnya yang sederhana dan penangkapan dilakukan secara one day fishing. Alat tangkap yang biasa digunakan oleh nelayan untuk menangkapnya adalah jaring lobster. Jaring ini terbuat dari nylon, dengan ukuran lebar $30 \mathrm{~m}$, panjang bisa mencapai $70 \mathrm{~m}$ dan mata jaring berukuran 2 inci. Penangkapan lobster biasanya dilakukan berdua, biasanya masing-masing membawa jaring penangkap yang bisa mencapai jumlah 30 pis, jaring penangkap tersebut kemudian dipasang di tengah laut dan menyentuh hingga ke dasar. Nelayan biasanya berangkat ke laut sejak jam 4.30 pagi dan kembali ke darat jam 16.00. Dalam sebulan biasanya ada satu hari libur yaitu hari Jumat kliwon. Hal ini erat kaitannya dengan kultur budaya setempat. Hasil tangkapan yang diperoleh langsung dijual ke bakul/pengepul yang ada di sekitar Sadeng. Lobster yang dijual biasanya harus dalam keadaan hidup. Jika lobster tersebut mati maka harganya akan turun drastis yakni hanya mencapai $20 \%$ dari harga normal.

Penangkapan lobster ini turut mendapat dukungan dari pemerintah. Hal ini ditunjukkan dengan adanya bantuan berupa uang yang digunakan untuk pembelian alat tangkap jaring lobster. Bantuan itu merupakan bagian dari program Pengembangan Usaha Mina Pedesaan (PUMP) Perikanan Tangkap dari Direktorat Jendral Perikanan Tangkap pada tahun 2012. Dari uang sebesar 10 juta rupiah tersebut yang diterima oleh masing-masing anggota dapat dibelikan jaring berjumlah 30 pis. Ada sekitar 9 kelompok yang mendapat bantuan termasuk kelompok nelayan penangkap lobster.
Biaya operasional melaut yang dikeluarkan oleh nelayan untuk pembelian bensin, rokok dan makan. Bensin yang dibutuhkan sebanyak 20 liter dengan harga Rp 8.000,-/liter. Rokok yang dibawa sebanyak 3 bungkus dengan harga per bungkusnya Rp 10.000,-. Total biaya yang dihabiskan mencapai Rp 200.000,-/trip.

Sistem bagi hasil yang diterapkan dalam penangkapan lobster sebagai berikut. Nilai dari hasil tangkapan kotor terlebih dahulu dikurangi dengan biaya bahan bakar. Selanjutnya jika pemilik memiliki perahu, mesin dan membawa alat tangkap sendiri maka ia mendapat 3 bagian sedangkan jika alat tangkap miliknya digunakan secara bersama maka ia mendapat tambahan $25 \%$ dari hasil tangkapan bersih. Penangkapan lobster ini menjadi sumber mata pencaharian utama rumah tangga yang cukup menjanjikan karena jika musim sedang bagus maka dalam sehari si penangkap ikan dapat membawa pulang uang bersih sejumlah Rp 300.000,-/ trip. Salah satu tantangan yang dihadapi oleh penangkap lobster adalah cuaca. Cuaca yang kurang baik seperti musim hujan dan ombak sedang tinggi merupakan saat-saat sedang ada musim lobster. Hal ini tentunya harus mendapat dukungan jaminan keselamatan untuk mengurangi resiko seperti penggunaan pelampung atau mengikuti program asuransi yang ada dengan membayar premi yang sesuai dengan kemampuan ekonominya.

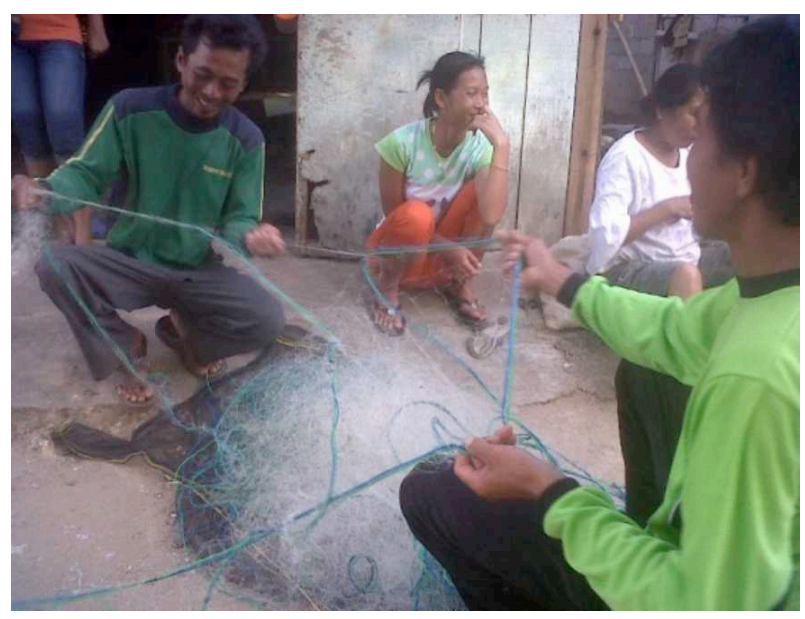

\section{Gambar 6. Nelayan Penangkap Lobster sedang} Memperbaiki Jaring.

Sumber : Dokumen Pribadi, 2013

Meskipun harga lobster sangat menarik, penangkapan lobster secara illegal harus dihindari karena dapat merusak keberlangsungan Sumber Daya Ikan (SDI). Menurut Moosa dan Aswandy (1984), ukuran panjang total lobster jantan dewasa kurang lebih 20 $\mathrm{cm}$, dan betina kurang lebih $16 \mathrm{~cm}$, sedangkan umur pertama kali matang gonad yaitu ditaksir antara 5 tahun - 8 tahun. Usia matang gonad lobster yang cukup lama tersebut dan terjadi pengrusakan habitatnya seperti penggunaan potasium, bahan peledak dan racun sianida yang digunakan oleh oknum nelayan dapat 
mempercepat penurunan jumlah lobster. Oleh karena itu sumberdaya lobster perlu mendapat perhatian dari pemerintah setempat dari penangkapan secara ilegal.

\section{KESIMPULAN}

Sadeng mempunyai Pendaratan Ikan (PPI) yang bertaraf nasional dan merupakan penunjang pengembangan perikanan laut di Provinsi Daerah Istimewa Yogyakarta. Sadeng merupakan salah satu wilayah penghasil utama lobster di Kabupaten Gunungkidul karena hampir 32\% hasil tangkapan berasal dari wilayah Sadeng. Pada tahun 2012 produksi lobster dari wilayah Sadeng mencapai rata-rata 2,34 ton/bulan. Pemerintah pusat turut berperan untuk meningkatkan kesejahteraan nelayan dalam bentuk pemberian bantuan PUMP tahun 2012 melaui Dinas Kelautan dan Perikanan Gunungkidul. Ada beberapa kelompok nelayan penangkap lobster yang mendapat bantuan uang yang kemudian dibelikan jaring.

Lobster adalah komoditas perikanan yang memiliki nilai ekonomis tinggi dan harus dijaga kelestariannya. Penggunaan bahan berbahaya dalam penangkapan dapat merusak sumber keberlangsungan SDI nya. Oleh karena itu dibutuhkan peran dari pemerintah dan masyarakat untuk menjaga kelestarian lobster khususnya dan SDI pada umumnya.

\section{DAFTAR PUSTAKA}

Antara News. 2011. Gunung Kidul dorong nelayan perbanyak tangkapan. http://www.antaranews. com/print/327840/gunung-kidul-dorongnelayan-perbanyak-tangkapan. Diunduh tanggal 11 Desember 2013.

BBPI. 1996. Penangkapan Udang Barong dengan Menggunakan Krendet dan Gill Net (Jaring Insang) Lobster. Semarang

Dinas Kelautan dan Perikanan Kabupaten Gunungkidul 2012. Statistik Perikanan Tangkap Tahun 2012. Wonosari.

Moosa, M.K dan I. Aswandy. 1984. Jakarta : Proyek Studi Potensi Sumber Daya Alam Indonesia, Studi Potensi Sumber Daya Hayati Ikan. Lembaga Oseanologi Nasional, Lembaga IImu Pengetahuan Indonesia.

Rahayu, Y.S. 2008. Makin Banyak Nelayan Beralih Tangkap Lobster. http://yunisatiarahayu.blogspot. com/2008/11/makin-banyak-nelayan-beralihtangkap.html. Diunduh tanggal 27 Januari 2014. 